\title{
p38 $\beta$ MAPK mediates ULK1-dependent induction of autophagy in skeletal muscle of tumor-bearing mice
}

\author{
Zhelong Liü ${ }^{1,2,+}$, Ka Wai Thomas $\operatorname{Sin}^{1,+}$, Hui Ding ${ }^{1,3}$, HoangAnh Amy Doan ${ }^{1}$, Song Gao ${ }^{1}$, Hongyu Miao ${ }^{4}$, Yahui \\ Wei $^{1, \#}$, Yiman Wang ${ }^{1, \#}$, Guohua Zhang ${ }^{1, *}$, and Yi-Ping Li $^{1, *}$ \\ ${ }^{1}$ Department of Integrative Biology and Pharmacology, McGovern Medical School, University of Texas Health Science Center, \\ Houston, Texas 77030, USA. \\ ${ }^{2}$ Division of Endocrinology, Tongji Hospital, Tongji Medical College, Huazhong University of Science and Technology, Wuhan, China. \\ ${ }^{3}$ Department of Respiratory Medicine, Yixing Hospital affiliated to Jiangsu University, Yixing, China. \\ ${ }^{4}$ School of Public Health, University of Texas Health Science Center, Houston, Texas 77030, USA. \\ ${ }^{\dagger}$ These authors contributed equally. \\ \# Yahui Wei and Yiman Wang were medical students of Jiaotong University, Shanghai, China participating in the Summer Research \\ Program at McGovern Medical School, University of Texas Health Science Center at Houston. \\ * Corresponding Authors: \\ Yi-Ping Li, Department of Integrative Biology and Pharmacology, The University of Texas Health Science Center at Houston, 6431 \\ Fannin Street, Houston, Texas 77030, USA. ORCID ID: orcid.org/0000-0002-0811-2790. Tel: (713) 500-6498, Fax: (713) 500-0689; \\ E-mail: yi-ping.li@uth.tmc.edu; \\ Guohua Zhang, Department of Integrative Biology and Pharmacology, The University of Texas Health Science Center at Houston, \\ 6431 Fannin Street, Houston, Texas 77030, USA. Tel: (713) 500-6322, Fax: (713) 500-0689; E-mail: guohua.zhang@uth.tmc.edu
}

ABSTRACT Muscle wasting is the key manifestation of cancer-associated cachexia, a lethal metabolic disorder seen in over $\mathbf{5 0 \%}$ of cancer patients. Autophagy is activated in cachectic muscle of cancer hosts along with the ubiquitin-proteasome pathway (UPP), contributing to accelerated protein degradation and muscle wasting. However, established signaling mechanism that activates autophagy in response to fasting or denervation does not seem to mediate cancer-provoked autophagy in skeletal myocytes. Here, we show that p38 $\beta$ MAPK mediates autophagy activation in cachectic muscle of tumorbearing mice via novel mechanisms. Complementary genetic and pharmacological manipulations reveal that activation of $p 38 \beta$ MAPK, but not $p 38 \alpha$ MAPK, is necessary and sufficient for Lewis lung carcinoma (LLC)-induced autophagy activation in skeletal muscle cells. Particularly, muscle-specific knockout of p38 $\beta$ MAPK abrogates LLC tumor-induced activation of autophagy and UPP, sparing tumor-bearing mice from muscle wasting. Mechanistically, p38 $\beta$ MAPK-mediated activation of transcription factor C/EBP $\beta$ is required for LLC-induced autophagy activation, and upregulation of autophagy-related genes LC3b and Gabarapl1. Surprisingly, ULK1 activation (phosphorylation at S555) by cancer requires p38 $\beta$ MAPK, rather than AMPK. Activated ULK1 forms a complex with $p 38 \beta$ MAPK in myocytes, which is markedly increased by a tumor burden. Overexpression of a constitutively active p38 $\beta$ MAPK in HEK293 cells increases phosphorylation at $\mathbf{S 5 5 5}$ and other amino acid residues of ULK1, but not several of AMPK-mediated sites. Finally, ULK1 activation is abrogated in tumor-bearing mice with muscle-specific knockout of $p 38 \beta$ MAPK. Thus, p38 $\beta$ MAPK appears a key mediator of cancer-provoked autophagy activation, and a therapeutic target of cancer-induced muscle wasting. doi: $10.15698 /$ cst2018.11.163

Received originally: 22.06.2018;

in revised form: 10.09.2018,

Accepted 24.09.2018,

Published 10.10.2018.

Keywords: cachexia, muscle wasting, C/EBPß, LC3b, Gabarapl1, ULK1.

\section{Abbreviations:}

AMPK - AMP-activated Protein Kinase,

C/EBPB - CCAAT/enhancer-binding protein beta,

GFP - Green fluorescence protein, HSP - Heat Shock Protein,

IL-6 - Interleukin 6

LCM - LLC Conditioned Medium,

LLC - Lewis Lung Carcinoma,

MAPK - Mitogen-Activated Protein

Kinase,

MKO - Muscle specific Knock Out,

TA - Tibialis Anterior,

TLR4 - Toll-Like Receptor 4,

ULK1 - Unc-51 Like autophagy

activating Kinase 1,

UPP - Ubiquitin-Proteasome

Pathway. 


\section{INTRODUCTION}

Cancer has been increasingly recognized as a systemic disorder that stresses multiple organs independent of its location. At least $50 \%$ of cancer patients experience cachexia, a systemic wasting syndrome manifested as weight loss, inflammation, insulin resistance, and increased muscle protein breakdown. Progressive loss of muscle mass (muscle wasting) contributes significantly to cancer-associated morbidity and mortality [1, 2]. However, the etiology of cancer cachexia is not well defined and there is no FDAapproved treatment for this lethal disorder.

There has been a general consensus that accelerated muscle protein degradation is a major cause of cachexiaassociated muscle mass loss. It has been well-established that the ubiquitin proteasome pathway (UPP) plays an important role in cancer-induced muscle wasting by degrading myofibrillar proteins [3-5]. More recent evidence indicates that cancer also induces autophagy activation in the cachectic muscle of tumor-bearing mice [6-9] and cancer patients [10-12]. Autophagy targets cytoplasmic constituents including ubiquitinated protein aggregates and organelles for degradation by lysosomes [13, 14]. Autophagy inhibition blocks muscle protein degradation induced by the activation of Toll-like receptor 4 (TLR4) [15], a plasma membrane receptor that is activated by danger-associated molecular patterns (DAMPs)[16] and mediates cancerinduced muscle wasting $[4,9,17]$. Thus, cancer-provoked autophagy activation is considered a therapeutic target of cancer-induced muscle wasting. However, the intramuscular signaling pathways that mediate cancer-induced activation of autophagy remain poorly understood. Elucidating and thereby targeting the cellular signaling pathways that mediate cancer-induced activation of autophagy could allow intervention of cancer-induced muscle wasting.

The Akt-FoxO signaling pathway inversely mediates the activity of both autophagy and UPP in muscle in response to such catabolic stimuli as fasting or denervation $[18,19]$. However, Akt is activated in cachectic muscle of tumorbearing mice $[20,21]$ and cancer patients $[11,12]$, which inhibits FoxOs by promoting their translocation out of nuclei [22]. Thus, the Akt-FoxO signaling pathway does not appear to mediate cancer-induced muscle catabolism that is due largely to systemic inflammation. On the other hand, we observed previously that inflammation activated-p38 MAPK mediates both the autophagy and UPP activation in skeletal muscle in response to TLR4 activation by lipopolysaccharide [15]. Other inflammatory mediators implicated in cancer cachexia also activate p38 MAPK including oxidative stress [23], TNF $\alpha$ [24], IL-6 [25], IL-1 [26], TWEAK [27], activin A/myostatin [28] as well as extracellular Hsp70 and Hsp90 [4], while promoting autophagy and/or UPPmediated muscle protein loss. However, it is unknown which of the three p38 MAPK isoforms that are expressed in skeletal muscle $(\alpha, \beta$, and $\gamma$ ) mediates cancer-induced autophagy activation. More importantly, how p38 MAPK activates autophagy is unknown.
In the present study, we demonstrate that activation of the $p 38 \beta$ MAPK isoform is necessary and sufficient for autophagy activation in skeletal muscle in a mouse model of cancer cachexia, and that deletion of p38 $\beta$ MAPK in skeletal muscle abrogates muscle wasting by attenuating muscle protein degradation mediated by autophagy as well as UPP. Mechanistically, p38 $\beta$ MAPK mediates cancer-provoked autophagy activation by upregulating Atg8 orthologues LC3b and Gabarapl1 as well as by activating ULK1. These data support $p 38 \beta$ MAPK as a key mediator and therapeutic target of cancer-associated muscle wasting.

\section{RESULTS}

\section{LLC induces autophagy activation in skeletal muscle cells through p38 $\beta$ MAPK}

We previously showed that LLC induces an increase in autophagy flux and autophagosome formation in cultured C2C12 myotubes as well as mouse muscle [9]. In the present study, we further investigated whether LLC induces autophagy activation in skeletal muscle cells through p38 MAPK by monitoring the autophagy marker LC3-II. By pretreating $\mathrm{C} 2 \mathrm{C} 12$ myotubes, which respond to cancer cellconditioned media in a similar manner as primary myotubes [4], with a $p 38 \alpha / \beta$ MAPK inhibitor SB202190, we observed that the induction of autophagy by LLC cellconditioned medium (LCM) required p38 MAPK activation (Figure 1A). In addition, systemic administration of SB202190 to LLC tumor-bearing mice inhibited autophagy activation in cachectic muscle (Figure 1B). These results suggest that LLC induces autophagy activation in skeletal muscle through the activation of $p 38 \alpha$ and/or p38 $\beta$ MAPK.

To identify the isoform of p38 MAPK that mediated LLC induction of autophagy, we utilized siRNA-mediated gene silencing and observed that the loss of $p 38 \beta$ MAPK, but not p38 $\alpha$ MAPK, abolished LCM-induced autophagy activation (Figure 1C). To examine whether activated p38 $\beta$ MAPK actually stimulated autophagy flux, a constitutively active mutant of p38 $\alpha$ MAPK or p38 $\beta$ MAPK [29] was expressed in myotubes. Only the active p38 $\beta$ MAPK increased the LC3-II level. In addition, treatment of myotubes with lysosome inhibitor chloroquine (CQ) further increased LC3-II in active p38 $\beta$ MAPK-expressing myotubes. Further, expression of active p38 $\beta$ MAPK resulted in a loss in the autophagy-selective target $p 62$, and $C Q$ treatment abrogated this effect (Figure 1D). These results indicate that p38 $\beta$ MAPK activation stimulated autophagy flux. Similarly, LC3-II was specifically increased by the overexpressed active mutant of $p 38 \beta$ MAPK in the muscle (TA) of tumor-free mice (Figure 1E). Furthermore, co-transfection of GFP-LC3 with active p38 $\beta$ MAPK, but not active p38 $\alpha$ MAPK, in mouse muscle resulted in increased autophagosome formation as indicated by the formation of GFP-LC3-incorporated puncta (Figure 1F). These data provided evidence that p38 $\beta$ MAPK activation is necessary and sufficient for autophagy activation in skeletal muscle cells by a tumor burden. 

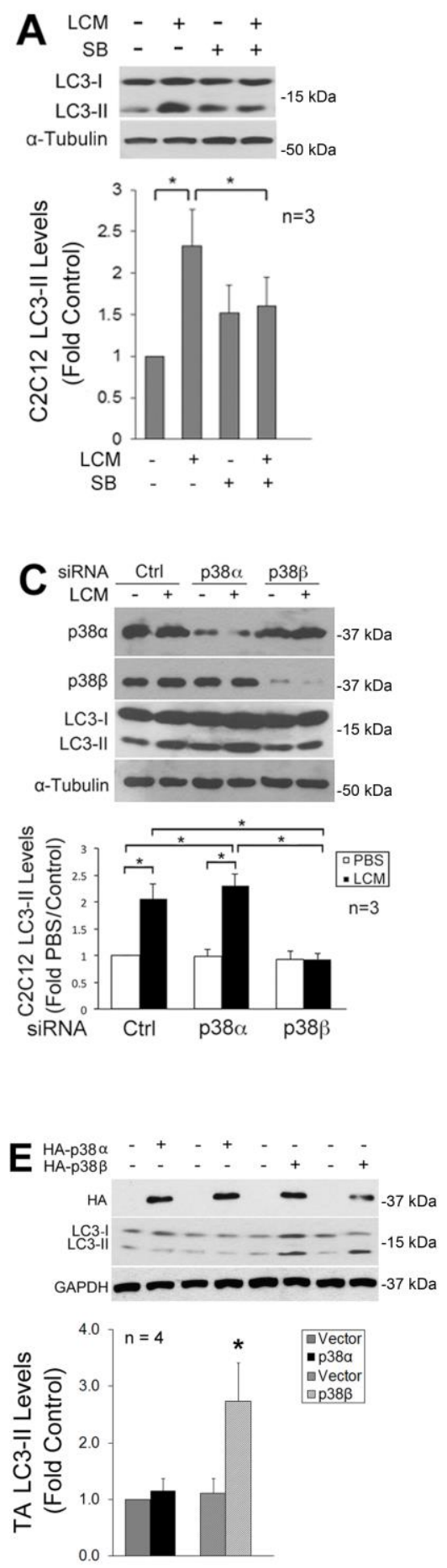
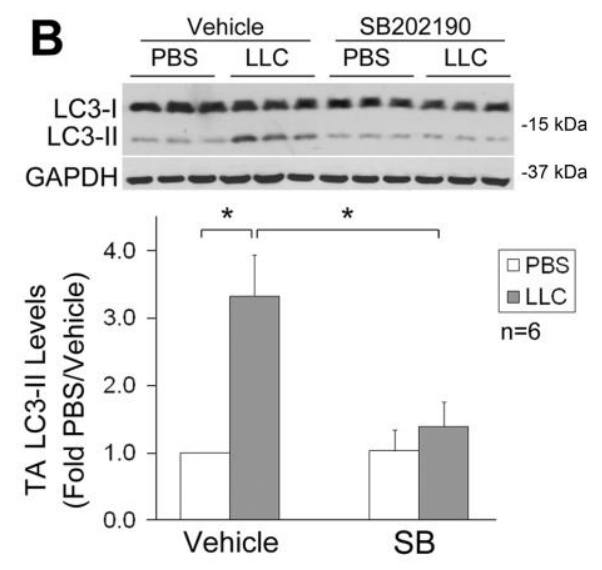

D Plasmid $\frac{\text { Vector }}{-} \frac{\mathrm{p} 38 \alpha}{-+} \frac{\mathrm{p} 38 \beta}{-+}$

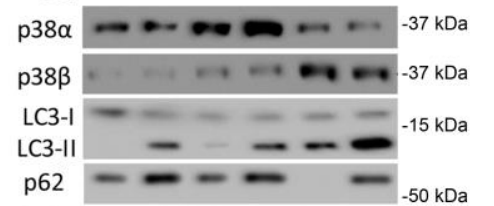

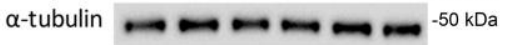
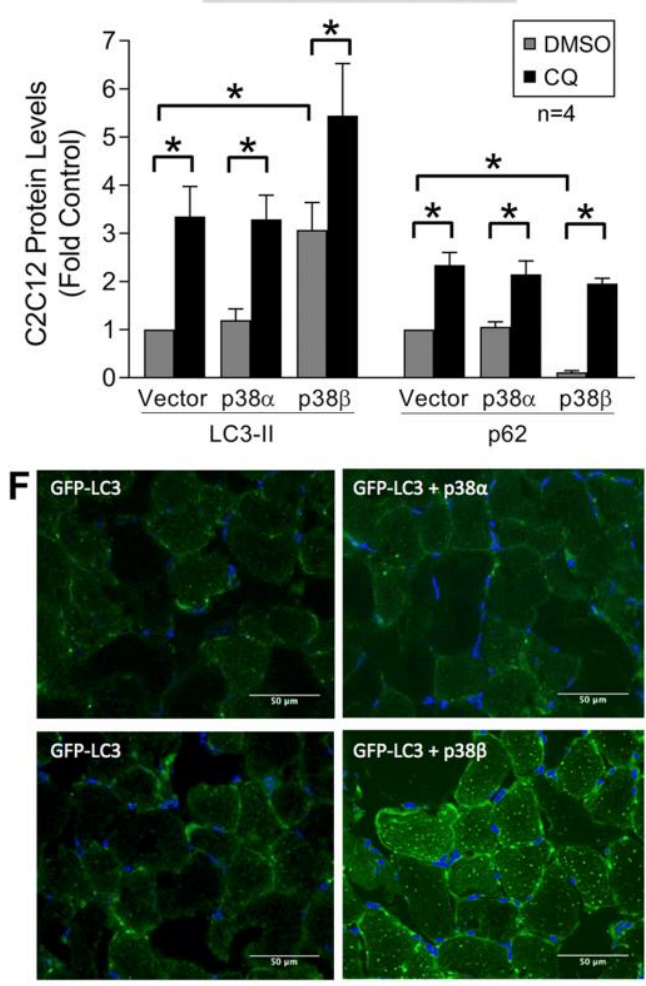

FIGURE 1: $\mathrm{p} 38 \beta$ MAPK activation is necessary and sufficient for autophagy activation by tumor in skeletal muscle cells. (A) Inhibition of p38 MAPK attenuates LLCconditioned medium (LCM)-induced autophagy activation in C2C12 myotubes. C2C12 myotubes were pretreated with SB202190 (SB, $10 \mu \mathrm{M})$ or vehicle (0.1\% DMSO) for $30 \mathrm{~min}$ prior to treatment with LCM or control medium (NL20) for $8 \mathrm{~h}$. Autophagy activation was evaluated by Western blotting analysis of LC3 in cell lysate. (B) Inhibition of p38 MAPK attenuates autophagy activation in skeletal muscle of LLC tumor-bearing mice. In 7 days of LLC implant to mice, SB202190 was i.p. injected (5 mg/kg) daily with DMSO (50\%) as vehicle control for 14 days. Lysate of TA collected on 21 days of LLC implant was analyzed by Western blotting for LC3 (samples from 3 mice per group were loaded on each gel). (C) LCM-induced autophagy activation in myotubes is dependent on p38 $\beta$ MAPK. C2C12 myoblasts were transfected with control, p38 $\alpha$ MAPK or p38 $\beta$ MAPK-specific siRNA. After differentiation, myotubes were treated with LCM or control medium for $8 \mathrm{~h}$. Autophagy activation was evaluated by Western blotting analysis of LC3. (D) Expression of constitutively active p38 $\beta$ MAPK stimulates autophagy flux in C2C12 myotubes. Plasmids encoding a constitutively active mutant of $p 38 \alpha$ MAPK or $p 38 \beta$ MAPK with the HA tag were transfected into $\mathrm{C} 2 \mathrm{C} 12$ myoblasts, with empty vector as control. After differentiation, myotubes were treated with chloroquine $(\mathrm{CQ}, 20 \mu \mathrm{M})$ for $8 \mathrm{~h}$. LC3, p62 and expression of the p38 MAPK mutants were monitored by Western blotting. (E) Constitutively active p38 $\beta$ MAPK activates autophagy in mouse muscle. Plasmids encoding the constitutively active mutant of p38 $\alpha$ MAPK or p38 $\beta$ MAPK fused with the HA tag were transfected into the TA of mice. Empty vector was transfected into the contralateral TA. On day 14 expression of the p38 MAPK mutants and autophagy activation was analyzed by Western blotting (data from two mice per group are shown). Data were analyzed by one way ANOVA. * denotes a difference between bracketed groups or from controls $(p<0.05)$. (F) Constitutively active $\mathrm{p} 38 \beta$ MAPK stimulates autophagosome formation in mouse muscle. A plasmid encoding GFP-LC3 was transfected into mouse TA muscle, and co-transfected with the plasmid encoding the constitutively active mutant of p38 $\alpha$ MAPK or p38 $\beta$ MAPK in the contralateral TA. In 7 days, TA muscle was collected. Frozen sections were prepared and stained with DAPI. Autophagosome formation was evaluated by confocal microscopy. Bars represent $50 \mu \mathrm{m}$. 
LLC induces muscle wasting through p38 $\beta$ MAPKmediated activation of autophagy and UPP

Next, we investigated whether LLC-induced activation of autophagy and muscle wasting are attenuated in the muscle of mice with muscle-specific knockout of p38 $\beta$ MAPK (p38 $\beta$ МKO) [30]. It was previously shown that the muscle phenotype was not altered by deleting the $p 38 \beta$ gene $[28$, $30,31]$. We observed that $p 38 \beta$ MKO mice were resistant to LLC-induced autophagy activation as measured by LC3-II and $\mathrm{p} 62$ levels (Figure 2A). In addition, p38 $\beta$ MKO mice were resistant to LLC-stimulated UPP activity as monitored by the levels of atrogin1, UBR2 and myofibrillar protein myosin heavy chain (MHC) (Figure 2B). Consequently, p38 $\beta$ MKO mice were spared from LLC-induced muscle wasting without altering tumor growth as measured by tumor weight, body and muscle weight, muscle proteolysis (tyrosine release), muscle strength (grip strength, Figure 2C) and myofiber cross-sectional area (Figure 2D). Thus, LLC induces muscle wasting through p38 $\beta$ MAPK-mediated activation of both autophagy and UPP.

\section{p38 $\beta$ MAPK-mediated C/EBP $\beta$ activation is critical to LLC- induced autophagy activation}

We previously showed that p38 $\beta$ MAPK mediates LLCinduced upregulation of atrogin1 [29] and UBR2 [32] through the activation of C/EBP $\beta$-binding to a cis-element in their 5 '-promoter by phosphorylating the Thr-188 residue of C/EBP $\beta$ [29], and that LLC-induced muscle wasting is abrogated in C/EBP $\beta$ knockout mice [21]. We therefore investigated whether the $\mathrm{p} 38 \beta \mathrm{MAPK} \rightarrow \mathrm{C} / \mathrm{EBP} \beta$ signaling pathway also mediates LLC activation of autophagy. We observed that LLC-induced activation of C/EBP $\beta$ was blocked in the muscle of p38 $\beta$ MKO mice (Figure $3 \mathrm{~A}$ ), confirming in vivo that $\mathrm{p} 38 \beta$ MAPK mediates LLC-induced activation of C/EBP $\beta$. To investigate whether $C / E B P \beta$ is critical to LLC-induced autophagy activation, we treated C/EBP $\beta$ deficient $\mathrm{C} 2 \mathrm{C} 12$ myotubes with LCM, and observed a dependence of LCM-induced autophagy activation on C/EBP $\beta$ (Figure 3B). Further, we observed that LLC-induced autophagy activation was abrogated in the muscle of C/EBP $\beta$ knockout mice (Figure 3C). Thus, p38 $\beta$ MAPK-mediated activation of C/EBP $\beta$ is critical to LLC-induced autophagy activation.

\section{p38 $\beta$ MAPK $\rightarrow$ C/EBP $\beta$ signaling mediates upregulation of specific autophagy-related genes}

To understand how C/EBP $\beta$ mediates LLC-induced autophagy activation, we searched a data base (http://tfbind.hgc.jp/) for potential C/EBP $\beta$-binding sites in the $5^{\prime}$-promoter regions of autophagy-related genes and identified multiple sites within -1 kilo-bases in five important autophagy related genes (Figure 4A). By analyzing mRNA levels of these genes in the muscle of LLC tumorbearing wild type and C/EBP $\beta$ knockout mice, we found that mRNA of LC3b and Gabarap/1, two Atg8 orthologues, were upregulated by LLC in a C/EBP $\beta$-dependent manner (Figure 4B). Corroborative data were obtained in $\mathrm{C} 2 \mathrm{C} 12$ myotubes where LCM treatment upregulated the two genes in a C/EBP $\beta$-dependent manner (Figure $4 \mathrm{C}$ ). To determine whether LLC stimulates C/EBP $\beta$ binding to the two gene promoters, we performed the chromatin immunoprecipitation (ChIP) assay and observed that LCM treatment of $\mathrm{C} 2 \mathrm{C} 12$ myotubes stimulated $\mathrm{C} / \mathrm{EBP} \beta$ binding to multiple sites in the $L C 3 b$ and Gabarapl1 promoter (Figure 4D). These data suggest that C/EBP $\beta$ upregulates the two Atg8 orthologues in muscle cells in response to a tumor burden.

To verify whether $\mathrm{p} 38 \beta$ MAPK is required for C/EBP $\beta$ mediated upregulation of $\angle C 3 b$ and Gabarapl1, we observed that the upregulation of these genes in LCM-treated myotubes was inhibited by SB202190 (Figure 5A). Further, upregulation of these genes in skeletal muscle was abrogated in LLC tumor-bearing p38 $\beta$ MKO mice (Figure 5B). These data confirm that LLC upregulates $\angle C 3 b$ and Gabarapl1 through the p38 $\beta$ MAPK $\rightarrow$ C/EBP $\beta$ signaling pathway.

\section{LLC induces ULK1 activation in skeletal muscle through p38 $\beta$ MAPK}

Both LC3b and Gabarapl1 are members of the ATG8 family that are essential for autophagosome formation [33]. On the other hand, ATG8 family members must be activated by the ULK1 complex post-translationally to initiate the lipidation process required for autophagsome formation [34]. Therefore, we examined whether LLC induced ULK1 activation in skeletal muscle cells. LCM treatment of C2C12 myotubes for $1 \mathrm{~h}$ increased ULK1 phosphorylation on Ser555 (pS555-ULK1, Figure 6A). Phosphorylation of ULK1 on this serine residue is known to activate ULK1 by AMPactivated protein kinase (AMPK) upon nutrient deprivation $[35,36]$. LCM was shown previously to induce mTOR inhibition and AMPK activation in C2C12 myotubes [37]. To examine the involvement of AMPK in LCM-induced activation of ULK1, we pretreated myotubes with the AMPK inhibitor Compound C [38]. To our surprise, Compound $C$ did not alter LCM-induced ULK1 phosphorylation on Ser-555, although it did inhibit AMPK activation as measured by the phosphorylation state of its Thr-172 residue. However, pretreatment with p38 MAPK inhibitor SB202190 attenuated LCM-induced Ser-555 phosphorylation of ULK-1, without affecting LCM-induced Thr-172 phosphorylation of AMPK (Figure 6A). These data suggest that p38 MAPK, rather than AMPK, is critical to LCM-induced activation of ULK1. We then investigated whether p38 MAPK interacted with ULK1 by performing immunoprecipitation of p38 MAPK from myotube lysate. We observed co-precipitation of pS555-ULK1 with p38 MAPK in control myotubes, and that the level of co-precipitated pS555-ULK1 dramatically increased in LCM-treated myotubes (Figure 6B), suggesting that p38 MAPK does interact with ULK1 resulting in phosphorylation of its Ser-555 residue in myocytes, and this activity is stimulated upon p38 MAPK activation by a tumor burden. To identify the p38 MAPK isoform responsible for LCM-stimulated ULK1 phosphorylation on Ser-555, we performed siRNA-mediated gene silencing in myotubes and 

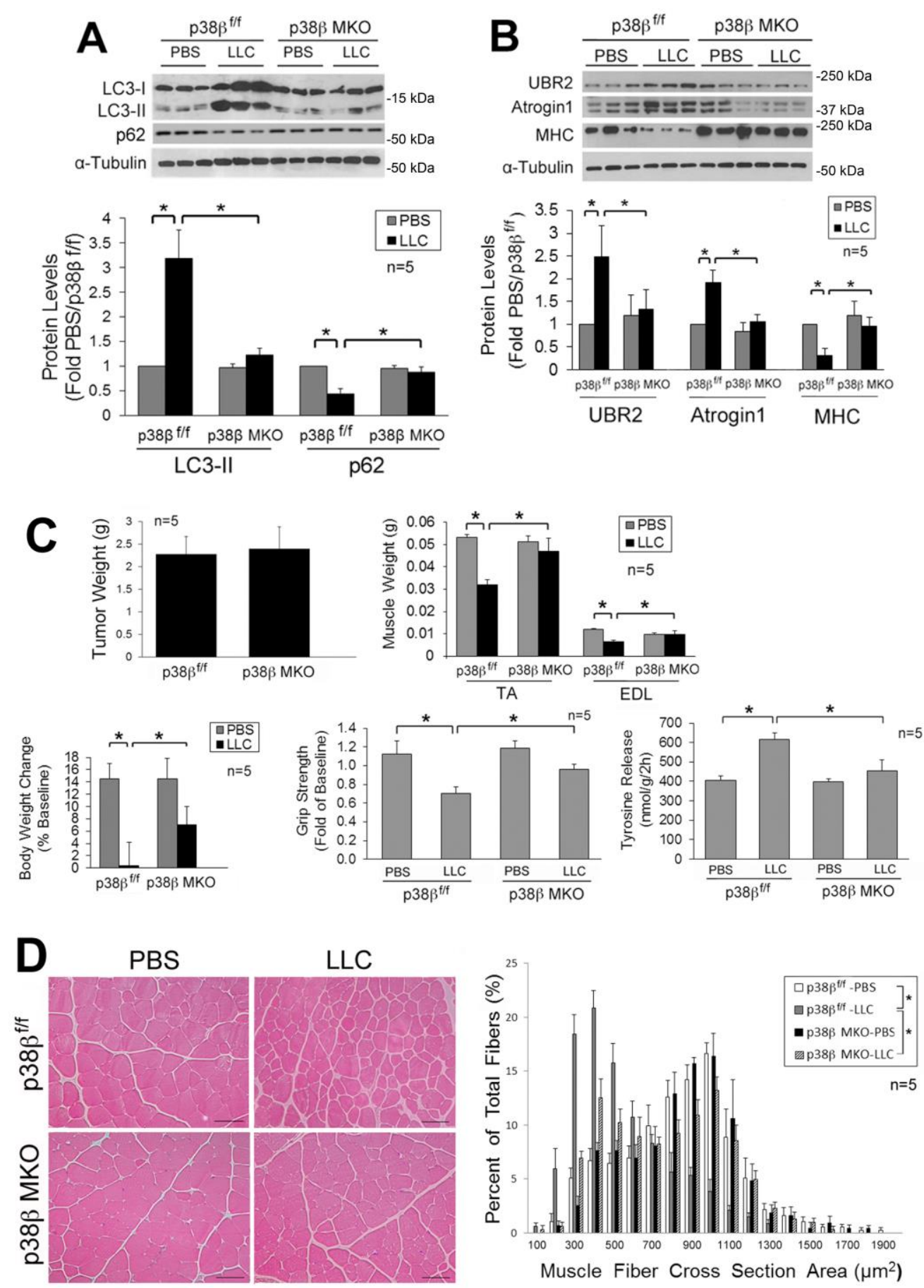

FIGURE 2: Muscle-specific knockout of $p 38 \beta$ MAPK abrogates activation of autophagy, UPP and muscle wasting in tumor-bearing mice. Mice with muscle-specific knockout of p38 $\beta$ MAPK and control mice (p38ß MAPK $\left.{ }^{f / f}\right)$ were implanted with LLC cells. In 21 days, mice were euthanized for analysis of muscle wasting. Lysate of TA collected from the mice was analyzed by Western blotting for LC3 and p62 to evaluate autophagy activity (A) and UBR2, atrogin1 and MHC to evaluate UPP activity (B). Muscle wasting in the mice was analyzed by examining tumor weight, body and muscle weight, tyrosine release and grip strength (C). Muscle mass was measured as muscle fiber cross sectional area (D). Data in A to $\mathrm{C}$ were analyzed by one way ANOVA. Data in D were analyzed by Chi-square analysis. ${ }^{*}$ denotes a difference $(p<$ 0.05).

observed that $p 38 \beta$ MAPK, but not $p 38 \alpha$ MAPK, was required for this reaction (Figure $6 \mathrm{C}$ ). To verify that activation of $\mathrm{p} 38 \beta$ MAPK is sufficient to phosphorylate ULK1, FLAG- tagged ULK1 was co-expressed with constitutively active p38 $\beta$ MAPK in HEK293T cells. Mass spectrometry analysis of FLAG-ULK1 isolated from cell lysate revealed multiple 
phosphorylated amino acid residues including Ser-555 (Supplementary Table 1). However, these sites did not include a number of known AMPK-mediated phosphorylation sites in ULK1 such as Ser-317, Ser-467, Ser-637 and Ser-777 [36, 39]. In combination, the above data support that $p 38 \beta$ MAPK stimulates ULK1 activity upon activation by cancer independent of AMPK in the cellular environment. Finally, we confirmed that Ser-555 phosphorylation of ULK1 increased in the muscle of LLC tumor-bearing $\mathrm{p} 38 \beta^{\mathrm{f} / \mathrm{f}}$ mice but not in that of muscle-specific p38 $\beta$ MAPK knockout mice. On the other hand, LLC-induced AMPK activation was not altered in p38 $\beta$ MAPK-deficient muscle (Figure 6E). Therefore, we conclude that p38 $\beta$ MAPK, rather than AMPK, mediates LLC-induced autophagosome formation by activating ULK1 in addition to upregulating LC3b and Gabarapl1.

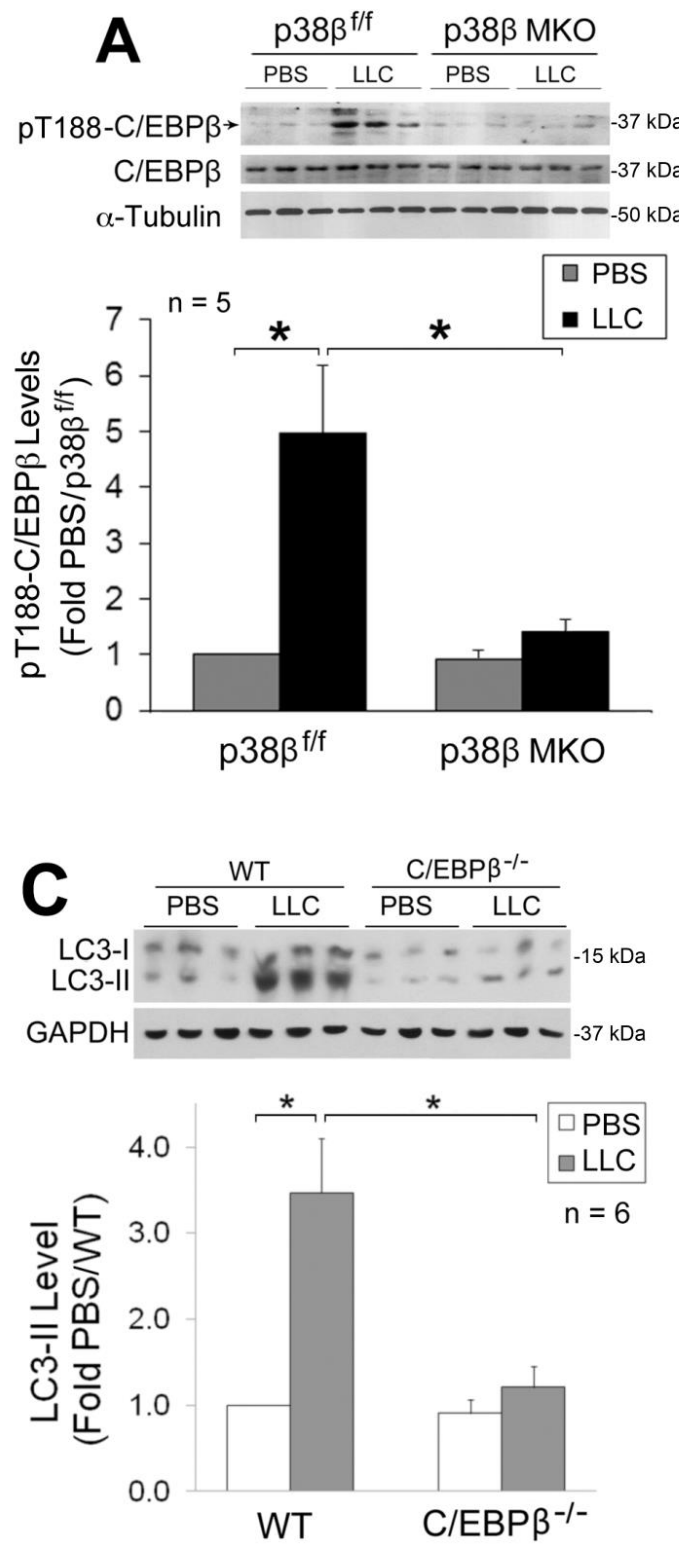

\section{DISCUSSION}

The current study identifies p38 $\beta$ MAPK as a key mediator of cancer-induced autophagy activation in skeletal muscle, through activating ULK1 as well as upregulating C/EBP $\beta$ controlled $L C 3 b$ and Gabarap/1 genes. Importantly, we were able to abrogate cancer-induced muscle wasting by deleting p38 $\beta$ MAPK in skeletal muscle to prevent muscle protein degradation mediated by autophagy as well as UPP. These findings suggest that $\mathrm{p} 38 \beta$ MAPK is a key mediator and a therapeutic target of cancer-induced muscle wasting.

We show that $\mathrm{p} 38 \beta$ MAPK upregulates $\angle C 3 b$ and Gabarapl1 through activating C/EBP $\beta$. The LC3 and Gabarapl family of proteins are mammalian orthologues of ATG8, a yeast autophagy-related protein involved in the formation of autophagosomes [33]. Increased expression of LC3/Gabaraple and activation of autophagy have been observed in cachectic muscle of cancer patients [10-12]. In

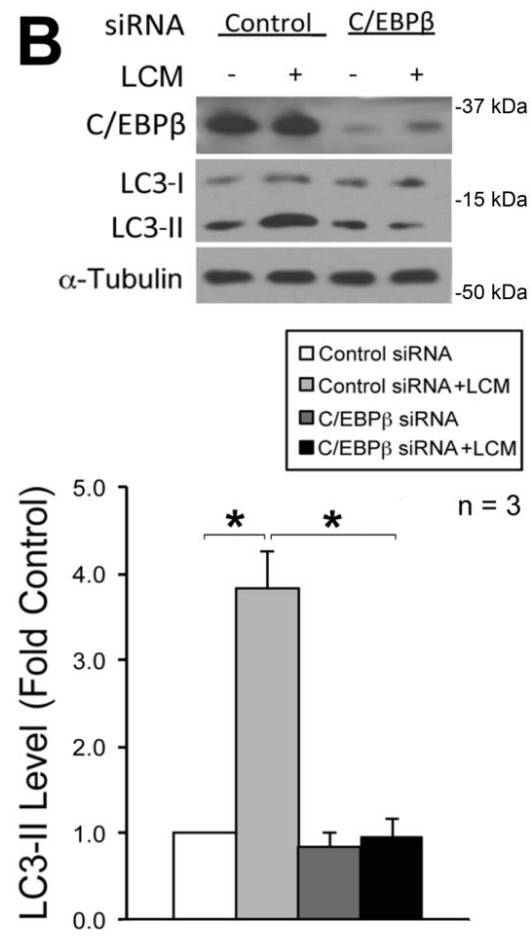

FIGURE 3: The $p 38 \beta$ MAPK $\rightarrow$ C/EBP $\beta$ signaling pathway mediates autophagy activation by tumor in skeletal muscle cells. (A) $C / E B P \beta$ activation in skeletal muscle of LLC tumor-bearing mice is dependent on $\mathrm{p} 38 \beta$ MAPK. Lysate of TA collected from $\mathrm{p} 38 \beta$ $\mathrm{MAPK}^{\mathrm{f} / \mathrm{f}}$ and $\mathrm{p} 38 \beta \mathrm{MAPK}$ muscle-specific knockout mice on day 21 of LLC implant was analyzed by Western blotting for C/EBP $\beta$ activation (phosphorylation of Thr-188). (B) C/EBP $\beta$ is critical to LCMinduced autophagy activation in myotubes. $\mathrm{C} 2 \mathrm{C} 12$ myoblasts transfected with control or C/EBP $\beta$-specific siRNA were treated with LCM or control medium for $8 \mathrm{~h}$. C/EBP $\beta$ and LC3 were analyzed by Western blotting. (C) Autophagy activation in skeletal muscle of LLC tumor-bearing mice is dependent on C/EBP $\beta$. Lysate of TA collected from wild type and C/EBP $\beta$ knockout mice on day 21 of LLC implant was analyzed by Western blotting for LC3. 
various types of cells, increased expression of LC3/Gabarapl are often associated with autophagy activation $[40,41]$. As the substrates of ULK1-mediated lipidation process that is critical for autophagosome formation [34], increased expression of LC3/Gabarapl is likely to facilitate autophagosome formation. On the other hand, the possibility exists that C/EBP $\beta$ may regulate additional autophagy-related genes that are rate-limiting for autophagosome formation.
Autophagy is activated by nutritional deprivation through AMPK-mediated phosphorylation of ULK1 on multiple sites including Ser-555 in various cell types $[35,36]$. In skeletal muscle, autophagy is also activated by the inactivation of Akt that inversely regulates FoxO3-mediated upregulation of autophagy-related gene expression in response to denervation or starvation $[18,42]$, or by AMPKmediated activation of $\mathrm{FoxO} 3$ in response to $\mathrm{C} 26$ colon adenocarcinoma [43]. We previously showed that LLC acti-
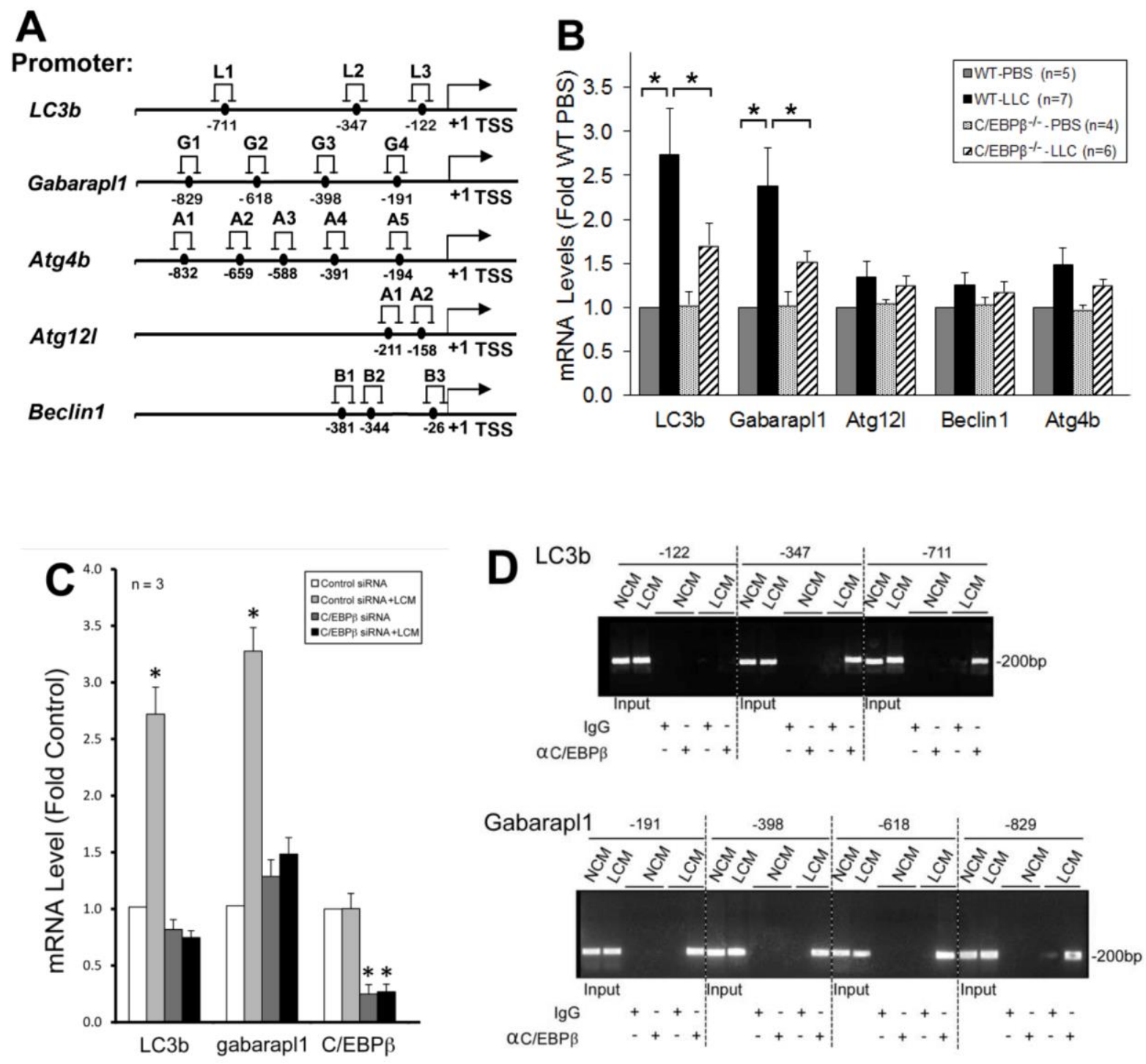

FIGURE 4. C/EBP $\beta$ mediates tumor induction of autophagy-related genes in skeletal muscle cells. (A) Potential C/EBP $\beta$-binding cites are identified in autophagy-related genes. Data base search identified multiple potential biding sites of C/EBP $\beta$ in the $5^{\prime}$ promoter region of listed autophagy-related genes. (B) $L C 3 b$ and Gabarap/1 are upregulated in skeletal muscle of LLC tumor-bearing mice in a C/EBP $\beta$ dependent manner. Total RNA was extracted from the TA of wild type and C/EBP $\beta$ knockout mice implanted with LLC cells for 21 days, and analyzed for the mRNA of above identified autophagy-related genes by real-time PCR. (C) LC3b and Gabarap/1 are upregulated in LCMtreated myotubes in a C/EBP $\beta$-dependent manner. Total RNA was extracted from C2C12 myotubes transfected with C/EBP $\beta$-specific or control siRNA. The mRNA of $C / E B P \beta, L C 3 b$ and Gabarapl1 was determined by real-time PCR. Data from panel B and C were analyzed by one way ANOVA. * denotes a difference ( $p<0.05)$. (D) LCM activates C/EBP $\beta$ binding to the $L C 3 b$ and Gabarapl1 promoters in myotubes. C/EBP $\beta$ binding to the $L C 3 b$ and Gabarap/1 promoters in C2C12 myotubes treated with LCM or the control NL20 cell-conditioned medium (NCM) was analyzed by the ChIP assay. Pre-immune IgG was used as control for C/EBP $\beta$-specific antibody. 
vates Akt and inactivates FoxO1/3 in muscle cells, while activating p38 MAPK concomitantly [21]. In the present study we show that despite AMPK activation by LLC in skeletal muscle, AMPK does not mediate in ULK1 activation LLC tumor-bearing mice. On the contrary, autophagy activation in skeletal muscle by LLC requires p38 $\beta$ MAPKmediated activation of ULK1. Thus, tumor activates autophagy in skeletal muscle through a signaling mechanism distinct from that in nutritional deprivation.

It is well-established that in skeletal muscle p38 MAPK is activated by various inflammatory mediators implicated in cancer cachexia including various cytokines [24-28], reactive oxygen species (ROS)[23] and extracellular vesicleassociated Hsp70 and Hsp90 [4]. Of the three members of p38 MAPK family expressed in skeletal muscle, p38 $\alpha$ MAPK is responsible for most of the known roles of p38 MAPK including mediating inflammation $[44,45]$ and promoting myogenesis $[46,47]$. p38ץ MAPK regulates the expansion of myogenic precursor cells [48], endurance exerciseinduced mitochondrial biogenesis and angiogenesis [30], as well as glucose uptake [49]. On the other hand, p38 $\beta$
MAPK has few known functions. Utilizing genetic manipulations including the $\mathrm{p} 38 \beta$ MAPK muscle specific knockout mice [30] in addition to pharmacological inhibition of $\mathrm{p} 38 \alpha / \beta$ MAPK (due to the lack of p38 $\beta$ MAPK-specific inhibitors), the current study demonstrated for the first time that $p 38 \beta$ MAPK is essential to autophagy activation during muscle wasting induced by LLC. The current study also demonstrated for the first time in vivo that $p 38 \beta$ MAPK is essential to UPP activation and muscle wasting induced by cancer. Therefore, developing p38 $\beta$ MAPK-specific pharmacological inhibitors would be highly desirable for the intervention of cancer cachexia.

Our findings on the role of $p 38 \beta$ MAPK in autophagy activation may have significance beyond skeletal muscle cells. For example, p38 MAPK mediates various stressinduced autophagy activation in a variety of cells [50-54]. Particularly, in response to TLR4 activation, p38 MAPK mediates autophagy activation associated with innate immunity [55], which is similar to cancer-induced muscle wasting $[4,9,17]$. However, which p38 MAPK isoform and how it activates autophagy in those processes are unknown. It is
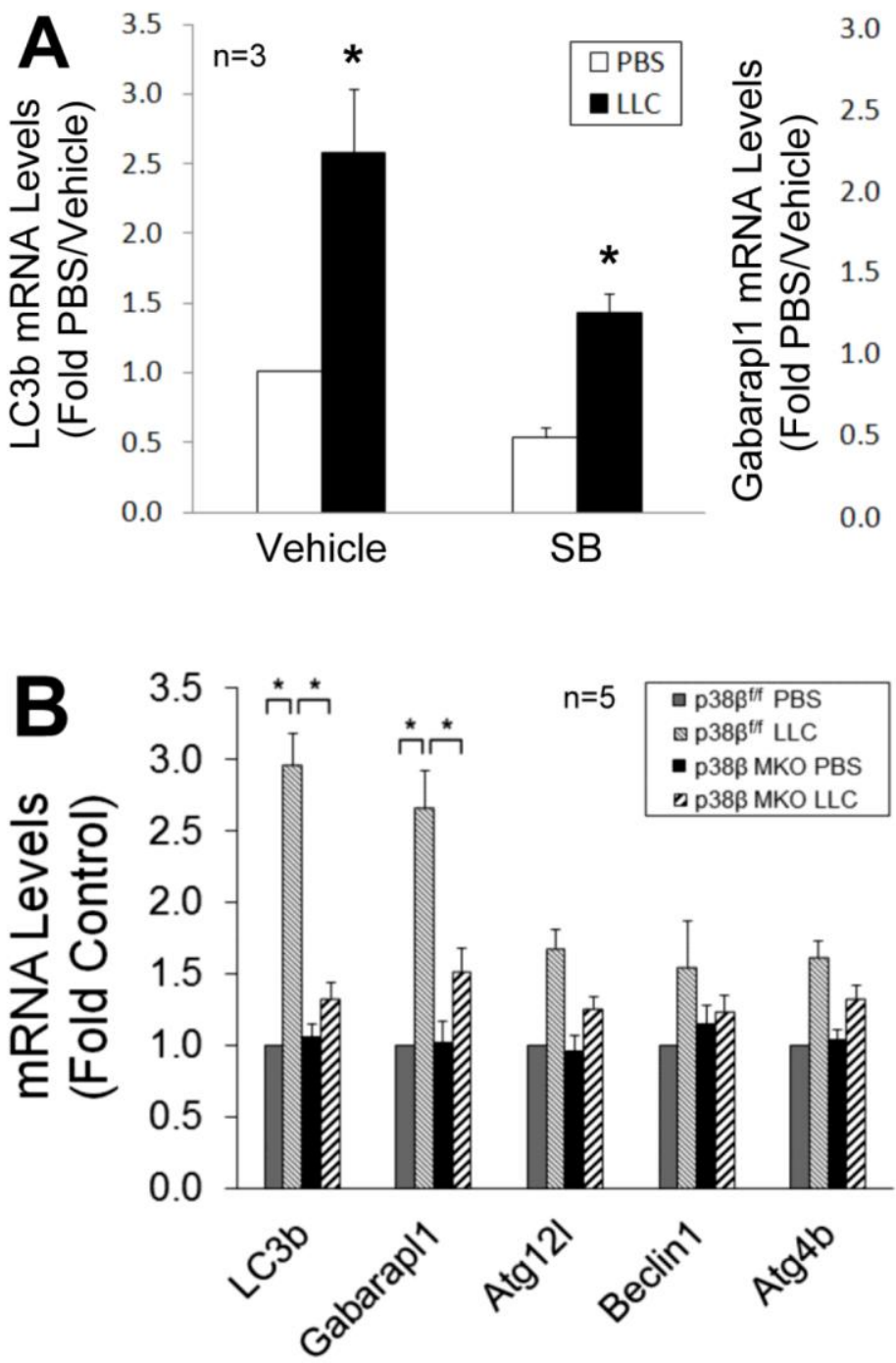

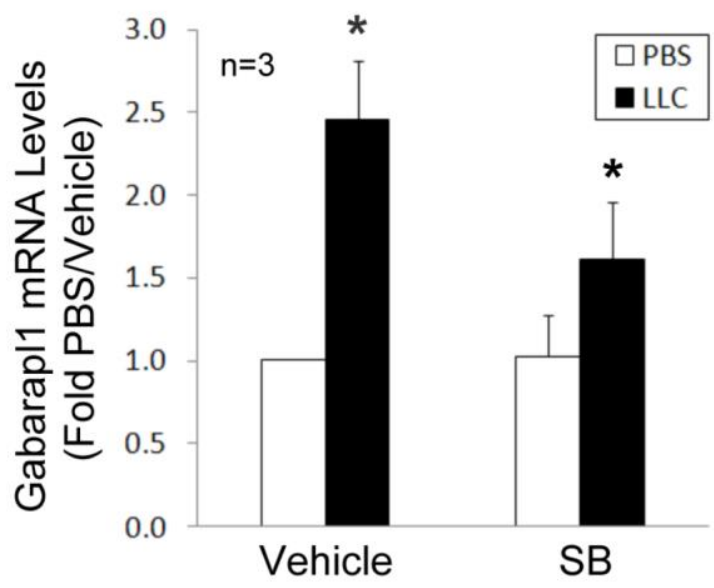

FIGURE 5: $p 38 \beta$ MAPK is required for upregulation of C/EBP $\beta$-responsive autophagy-related genes in cachectic muscle of tumor-bearing mice. (A) Inhibition of p38 MAPK attenuates $L C 3 b$ and Gabarap/1 upregulation in cachectic muscle of LLC tumor-bearing mice. On day 7 of LLC cells implant to mice, SB202190 was i.p. injected $(5 \mathrm{mg} / \mathrm{kg})$ daily with DMSO $(50 \%)$ as vehicle control. Lysate of TA collected on day 21 was analyzed by qPCR for $L C 3 b$ and Gabarapl1 mRNA levels. (B) $\angle C 3 b$ and Gabarap/1 upregulation in the muscle of LLC tumor-bearing mice is dependent on $p 38 \beta$ MAPK. Mice with musclespecific knockout of p38 $\beta$ MAPK (p38 $\beta$ MAPK MKO) or control mice ( $p 38 \beta \mathrm{MAPK}^{\mathrm{f} / \mathrm{f}}$ ) were implanted with LLC cells. On day 21, total RNA was extracted from TA of the mice and analyzed by qPCR for $\angle C 3 b$ and Gabarap/1 mRNA levels. Data were analyzed by one way ANOVA. * denotes a difference $(p<0.05)$. 

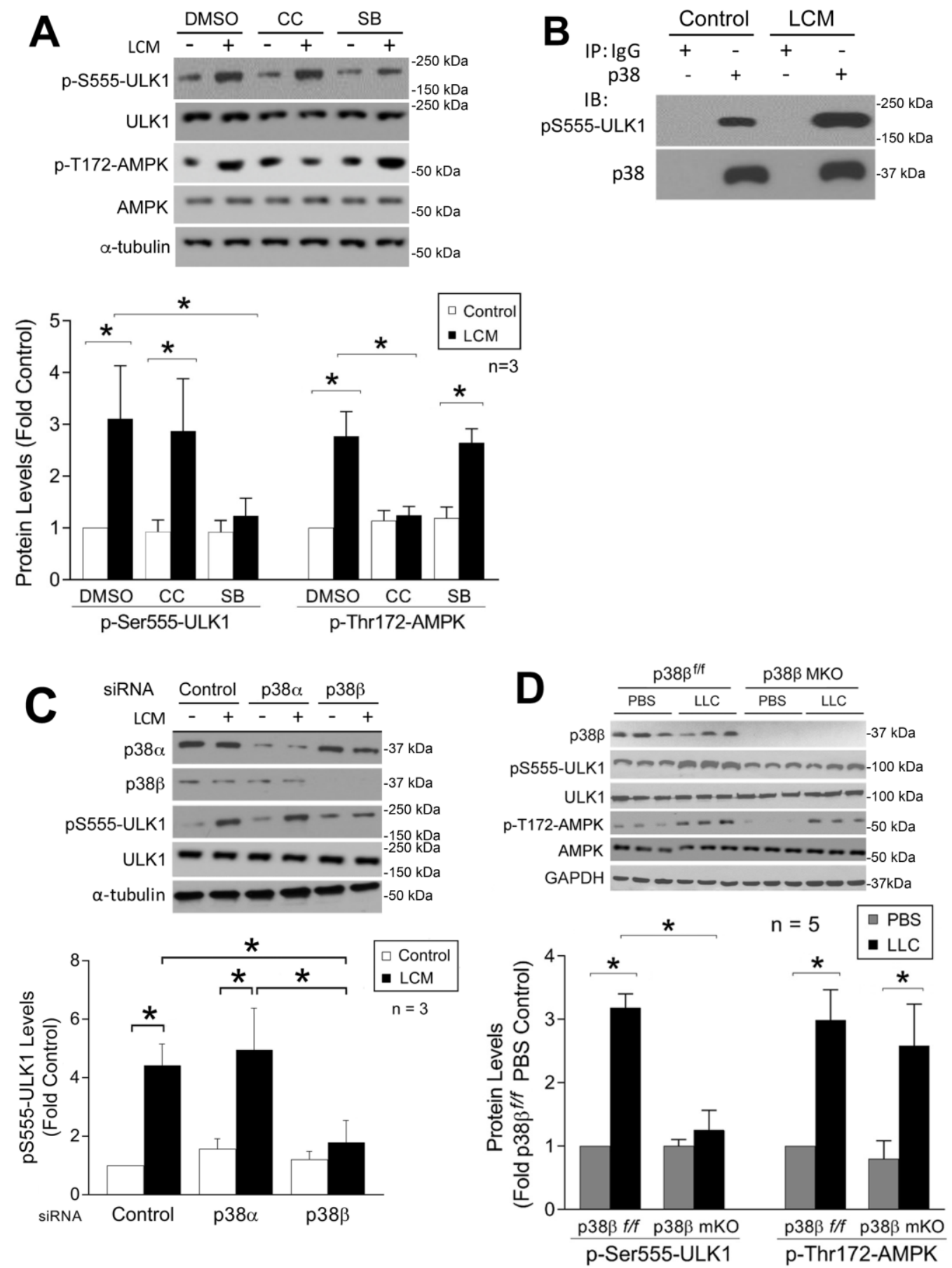

FIGURE 6: $p 38 \beta$ MAPK activates ULK1 in skeletal muscle cells in response to tumor. (A) LCM stimulates ULK1 phosphorylation on Ser-555 in myotubes through p38 MAPK. C2C12 myotubes were pretreated with DMSO (0.1\%, vehicle), compound C (CC, $10 \mu \mathrm{M})$ or SB202190 (SB, $10 \mu \mathrm{M}$ ) for $30 \mathrm{~min}$, and then treated with LCM for $1 \mathrm{~h}$. ULK1 phosphorylation state on Ser-555 and AMPK phosphorylation on Thr-172 in cell lysate were analyzed by Western blotting. (B) LCM stimulates p38 MAPK interaction with ULK1 in myotubes. C2C12 myotubes were treated with LCM for $1 \mathrm{~h}$. Cell lysate was subjected to immunoprecipitation with pre-immune IgG or p38 MAPK-specific antibody. Precipitate was analyzed by Western blotting for p38 MAPK and pSer-555 ULK1. (C) LCM stimulation of ULK1 phosphorylation on Ser-555 in myotubes is mediated by p38 $\beta$ MAPK specifically. C2C12 myoblasts were transfected with control, p38 $\alpha$ MAPK or p38 $\beta$ MAPK-specific siRNA. After differentiation for $96 \mathrm{~h}$, myotubes were treated with LCM or control medium for $1 \mathrm{~h}$. Knockdown of p38 MAPKs and phosphorylation of ULK1 on Ser-555 were analyzed by Western blotting. (D) p38 $\beta$ MAPK is required for ULK1 activation in cachectic muscle of LLC tumorbearing mice. Mice with muscle-specific knockout of p38 $\beta$ MAPK and control mice were implanted with LLC cells. Lysate of TA collected from these mice on day 21 was analyzed by Western blotting for ULK1 phosphorylation on Ser-555 and AMPK phosphorylation on Thr-172. Data were analyzed by one way AVOVA. * denotes a difference $(p<0.05)$. 
possible that a similar mechanism as we observed in skeletal muscle cells exists in other types of cells to mediate autophagy activation in response to inflammatory stresses.

Taken together, our findings reveal that p38 $\beta$ MAPK mediates cancer-induced autophagy in skeletal muscle through novel transcriptional as well as post-translational mechanisms. In addition, our findings suggest that cancerinduced muscle wasting can be ameliorated by targeting a single signaling molecule in skeletal muscle, p38 $\beta$ MAPK.

\section{MATERIALS AND METHODS \\ Myogenic cell culture}

Murine C2C12 myoblasts (American Type Culture Collection) were cultured in growth medium (DMEM supplemented with $10 \%$ fetal bovine serum) at $37^{\circ} \mathrm{C}$ with $5 \% \mathrm{CO}_{2}$. At $85-90 \%$ confluence, myoblast differentiation was induced by incubation for $96 \mathrm{~h}$ in differentiation medium (DMEM supplemented with $4 \%$ heat-inactivated horse serum) to form myotubes. Preconditioned medium from cultures of Lewis lung carcinoma cells (obtained from National Institute of Cancer, Frederick, MD) or non-tumorigenic human lung epithelial cell line NL2O (obtained from American Type Culture Collection) that were cultured for $48 \mathrm{~h}$ were centrifuged and the supernatant was used to treat $\mathrm{C} 2 \mathrm{C} 12$ myotubes (25\% final volume in fresh medium) when indicated. Pretreatment of SB202190 or compound C (10 $\mu \mathrm{M}$, dissolved in DMSO with $0.1 \%$ final concentration, Sigma-Aldrich, St. Louis, MO) for 30 min was carried out when indicated. All cell culture experiments were independently replicated 3 times as indicated $(\mathrm{N}=3)$.

\section{Animal use}

Experimental protocols were approved in advance by the institutional Animal Welfare Committee at the University of Texas Health Science Center at Houston. For LLC cell xenograft, $100 \mu \mathrm{lLC}$ (National Institute of Cancer) cells $\left(1 \times 10^{6}\right.$ cells), or an equal volume of vehicle (PBS) was injected subcutaneously into the right flanks of 7-week-old male C57BL/6 mice (The Jackson Laboratory, Bar Harbor, ME), $\mathrm{C} / \mathrm{EBP} \beta^{-1}$ mice in $\mathrm{C} 57 \mathrm{BL} / 6$ background that were bred from $\mathrm{C} / \mathrm{EBP} \beta^{-/+}$mice [56] or mice with muscle-specific knockout of p38 $\beta$ (p38 $\beta$ MKO) [28]. The latter were created by crossbreeding floxed-p38 $\beta$ mice $\left(p 38 \beta^{f / f}\right)$ in $\mathrm{C} 57 \mathrm{BL} / 6$ background [30] with muscle creatine kinase-Cre (MCK-Cre, The Jackson Laboratory, Bar Harbor, ME). SB202190 was i.p. injected ( $5 \mathrm{mg} / \mathrm{kg}$ ) daily from day 7 of tumor implant. Mice were euthanized on day 21 for evaluation of muscle wasting. When indicated plasmids encoding constitutively active mutant of p38 MAPK isoforms and GFPLC3 fusion protein [55] were transfected into TA by electroporation as previously described [29].

\section{Transfection of siRNA and plasmids in C2C12 myoblasts}

Predesigned siRNAs specific for C/EBP $\beta, p 38 \alpha$ and $p 38 \beta$ were purchased form Sigma-Aldrich. The IDs of the siRNAs were SASI_Mm01_00187563, SASI_Mm01_00020743 and SASI_Mm01_00044863, respectively. Control siRNA was purchased from Invitrogen. These siRNAs were introduced into C2C12 myoblasts using the jetPRIME reagent (Polyplustransfection Inc., Illkirch, France) according to the manufacturer's protocol. In $24 \mathrm{~h}$, myoblasts were differentiated and experiments were started in another $96 \mathrm{~h}$ when myotubes were formed. Plasmids encoding constitutively active $p 38 \alpha$ and $p 38 \beta$ isoforms [57] were transfected into C2C12 myoblasts using the jetPRIME reagent. Empty vector was transfected as the control. These manipulation of p38 MAPK in myoblasts did not alter the end result of differentiation and formation of myotubes [29].

\section{Real-time PCR}

Total RNA was isolated from myotubes or muscle by using TRIzol reagent (Invitrogen, Carlsbad, CA). Real-time PCR was performed as described previously [21]. Sequences of specific primers are listed in Table 1. Data were normalized to GAPDH.

\section{Western blot analysis}

Western blot analysis was carried out as described previously [24]. Antibodies to total and/or phosphorylated p38MAPK (T181/Y182), p-C/EBPß (T188), p-ULK1 (S555), total and phosphorylated AMPK (T172), p62 as well as $p 38 \alpha$ and $p 38 \beta$ were from Cell Signaling Technology (Beverly, MA). Antibody to C/EBP $\beta$ and ULK1 were from Santa Cruz Biotechnology (Santa Cruz, CA). Antibody to atrogin1/MAFbx was from ECM Biosciences (Versailles, KY). Antibodies to UBR2 and LC3-II were obtained from Novus Biologicals (Littleton, CO). Anti-MHC antibody (MF-20) was from R\&D Systems (Minneapolis, MN). Antibody to the HA tag was from Covance (Princeton, NJ, USA). Data was normalized to $\alpha$-Tubulin (antibody was from Development Studies Hybridoma Bank at the University of lowa, lowa City, IA) or GAPDH (Antibody was from Millipore, Billerica, MA, USA). Levels of phosphorylated proteins were normalized to corresponding total proteins.

\section{Chromosome immunoprecipitation (ChIP) assay}

ChIP assay was performed as previously described [21]. Antibody against C/EBP $\beta$ was from Santa Cruz Biotechnology. Preimmune IgG was from Sigma-Aldrich. The PCR primers used are listed in Table 1.

\section{Histology and confocal microscopy studies}

Cross sections of TA were fixed and stained with H\&E by the Histology Core at Lester and Sue Smith Breast Center, Baylor College of Medicine. Cross-sectional area of stained muscle sections was quantified by using the ImageJ software (NIH). Five view-fields with 100 myofibers per field in each section were measured. Frozen sections of mouse TA $(5 \mu \mathrm{m})$ that expressed GFP-LC3 and/or p38 MAPK mutant were stained with DAPI and examined with a Nikon A1R Confocal Laser Microscope using 60X objective.

Adjustment of brightness, contrast, color balance, and final image size was achieved using Adobe Photoshop CS (Adobe Systems, San Jose, CA, USA).

\section{Mapping of phosphorylated amino acid residues in ULK-1} HEK293T cells (American Type Culture Collection, Manassas, VA, USA) cultured in $150 \mathrm{~mm}$ plates that were $~ 50 \%$ confluent were co-transfected with a plasmid encoding mouse ULK-1 with a FLAG tag (Addgene) and a plasmid encoding constitutively active $p 38 \beta$ [58] (10 $\mu \mathrm{g}$ each) using the jetPRIME reagent (Polyplus-transfection Inc., Illkirch, France). The cell culture medium was replaced with fresh medium at $24 \mathrm{~h}$. After an additional incubation of $24 \mathrm{~h}$ cells were lysed in RIPA buffer (50 mM Tris- $\mathrm{HCl}$ (pH 7.5), $150 \mathrm{mM} \mathrm{NaCl}, 2$ mM EDTA, 1\% NP40, 0.1\% SDS, $2 \mathrm{mM}$ phenylmethylsulphonylfluoride (PMSF), 
TABLE 1. PCR primers used in this study.

\begin{tabular}{|c|c|c|}
\hline Primer & Sequence & \\
\hline $\begin{array}{l}\text { C/EBP } \beta \text { forward } \\
\text { C/EBP } \beta \text { reverse }\end{array}$ & $\begin{array}{l}\text { 5'-GACAAGCTGAGCGACGAGTACA } \\
\text { 5'-CGACAGCTGCTCCACCTTCTTC }\end{array}$ & \\
\hline $\begin{array}{l}\text { LC3b forward } \\
\text { LC3b reverse }\end{array}$ & $\begin{array}{l}\text { 5'-CGTCCTGGACAAGACCAAGT } \\
\text { 5'-ATTGCTGTCCCGAATGTCTC }\end{array}$ & \\
\hline $\begin{array}{l}\text { GABARAPL1 forward } \\
\text { GABARAPL1 reverse }\end{array}$ & $\begin{array}{l}\text { 5'-CATCGTGGAGAAGGCTCCTA } \\
\text { 5'-ATACAGCTGGCCCATGGTAG }\end{array}$ & \\
\hline $\begin{array}{l}\text { Atg12I forward } \\
\text { Atg12I reverse }\end{array}$ & $\begin{array}{l}\text { 5'-GGCCTCGGAACAGTTGTTTA } \\
\text { 5'-CAGCACCGAAATGTCTCTGA }\end{array}$ & \\
\hline $\begin{array}{l}\text { Beclin1 forward } \\
\text { Beclin1 reverse }\end{array}$ & $\begin{array}{l}\text { 5'-GGCCAATAAGATGGGTCTGA } \\
\text { 5'-CACTGCCTCCAGTGTCTTCA }\end{array}$ & \\
\hline $\begin{array}{l}\text { Atg } 4 b \text { forward } \\
\text { Atg } 4 b \text { reverse }\end{array}$ & $\begin{array}{l}\text { 5'-ATTGCTGTGGGGTTTTTCTG } \\
\text { 5'-AACCCCAGGATTTTCAGAGG }\end{array}$ & \\
\hline GAPDH forward & 5'-CATGGCCTTCCGTGTTCCTA & \\
\hline GAPDH reverse & 5'-GCGGCACGTCAGATCCA & Product size \\
\hline $\begin{array}{l}\text { LC3b }-122 \text { forward } \\
\text { LC3b -122 reverse }\end{array}$ & $\begin{array}{l}\text { 5'-GACAGTTAACAGATGCTC } \\
\text { 5'-AGTCCGCAGCCGAGTCAG }\end{array}$ & $198 \mathrm{bp}$ \\
\hline $\begin{array}{l}\text { LC3b }-347 \text { forward } \\
\text { LC3b -347 reverse }\end{array}$ & $\begin{array}{l}\text { 5'-GAGCCACAAGATCAGATC } \\
5^{\prime} \text {-TCATTCCCCTTCAGTCCT }\end{array}$ & $195 \mathrm{bp}$ \\
\hline $\begin{array}{l}\text { LC3b -711 forward } \\
\text { LC3b -711 reverse }\end{array}$ & $\begin{array}{l}\text { 5'-TGATTGCTCACCAACCAA } \\
\text { 5'-GACAACACCTGCTGTGCA }\end{array}$ & $198 \mathrm{bp}$ \\
\hline $\begin{array}{l}\text { Gabarapl1 -191 forward } \\
\text { Gabarapl1 -191 reverse }\end{array}$ & $\begin{array}{l}\text { 5'-AACTACCCTACAGGTGAT } \\
\text { 5'-CATCAAGGTTAGAAGAAG }\end{array}$ & $201 \mathrm{bp}$ \\
\hline $\begin{array}{l}\text { Gabarapl1 -398 forward } \\
\text { Gabarapl1 -398 reverse }\end{array}$ & $\begin{array}{l}\text { 5'-CTTATAAAATGAATGGAT } \\
\text { 5'-CTCCTTCTGACTGGTGTC }\end{array}$ & $199 \mathrm{bp}$ \\
\hline $\begin{array}{l}\text { Gabarapl1 }-618 \text { forward } \\
\text { Gabarapl1 }-618 \text { reverse }\end{array}$ & $\begin{array}{l}\text { 5'-CATAAGGACACCAGTCAG } \\
\text { 5'-GATGCCCAAAACAAACAC }\end{array}$ & $205 \mathrm{bp}$ \\
\hline $\begin{array}{l}\text { Gabarapl1 }-829 \text { forward } \\
\text { Gabarapl1 }-829 \text { reverse }\end{array}$ & $\begin{array}{l}\text { 5'-CATTGCTCTGGAAACAGC } \\
\text { 5'-CCAAGCTTTTCCTAAACC }\end{array}$ & $197 \mathrm{bp}$ \\
\hline
\end{tabular}

$0.5 \%$ sodium deoxycholate, $1 \mathrm{mM} \mathrm{NaF}, 1 / 100$ protease inhibitor cocktail, and 1/100 phosphatase inhibitor cocktail (SigmaAldrich, St. Louis, MO, USA). ULK-1 in cell lysates was precipitated using FLAG-M2 magnetic beads (Sigma-Aldrich) and subjected to $10 \%$ SDS-PAGE. The gel was then stained with Coommassie Blue R-250. The ULK1 band was cut out and subjected to tryptic phosphopeptide mapping conducted by Taplin Mass Spectrometry Facility at Harvard Medical School using an LTQ-Orbitrap mass spectrometer (Thermo Electron, West Palm Beach, FL, USA).

\section{Statistical analysis}

Data are presented as the mean \pm S.D. and were analyzed with one-way ANOVA or Student t test using the SigmaStat software (Systat Software, San Jose, CA) as indicated. When applicable, control samples from independent experiments were normalized to a value of 1 without showing variations (actual variations were within a normal range). Chi-square analysis was carried out by using $\mathrm{R}$ to compare the distributions of muscle fiber cross-sectional area among various groups. A $p$ value $<0.05$ was considered to be statistically significant.

\section{ACKNOWLEDGMENTS}

This study was supported by grants from National Institute of Arthritis and Musculoskeletal and Skin Diseases to Y.-P. Li (R01 AR063786 and AR067319). We thank Andrey Tsvetkov of UTHealth for helpful discussions, and David Engelberg (Hebrew University, Jerusalem, Israel) for sharing plasmids encoding the constitutively active mutants of p38 MAPK isoforms.

\section{SUPPLEMENTAL MATERIAL}

All supplemental data for this article are available online at www.cell-stress.com.

\section{CONFLICT OF INTEREST}

The authors declare that they have no conflict of interest.

\section{AUTHOR CONTRIBUTION}

Y-PL and GZ designed experiments and wrote the manuscript. GZ, ZL, KWTS, HD, HAD, SG, YW and YW conducted 
experiments, analyzed data and generated figures. HM analyzed data.

\section{COPYRIGHT}

(C) 2018 Liu et al. This is an open-access article released under the terms of the Creative Commons Attribution (CC BY) license, which allows the unrestricted use, distribution, and reproduction in any medium, provided the original author and source are acknowledged.

\section{REFERENCES}

1. Fearon K, Strasser F, Anker SD, Bosaeus I, Bruera E, Fainsinger RL, Jatoi A, Loprinzi C, Macdonald N, Mantovani G, Davis M, Muscaritoli M, Ottery F, Radbruch L, Ravasco P, Walsh D, Wilcock A, Kaasa S, Baracos VE (2011). Definition and classification of cancer cachexia: an international consensus. Lancet Oncol 12(5): 489-495. doi: 10.1016/S1470-2045(10)70218-7

2. Fearon KC, Glass DJ, Guttridge DC (2012). Cancer cachexia: mediators, signaling, and metabolic pathways. Cell Metab 16(2): 153166. doi: 10.1016/j.cmet.2012.06.011

3. Lecker SH, Jagoe RT, Gilbert A, Gomes M, Baracos V, Bailey J, Price SR, Mitch WE, Goldberg AL (2004). Multiple types of skeletal muscle atrophy involve a common program of changes in gene expression. FASEB J 18(1): 39-51. doi: 10.1096/fj.03-0610com

4. Zhang G, Liu Z, Ding H, Zhou Y, Doan HA, Sin KWT, Zhu ZJ, Flores R, Wen $Y$, Gong $X$, Liu Q, Li YP (2017). Tumor induces muscle wasting in mice through releasing extracellular $\mathrm{Hsp} 70$ and $\mathrm{Hsp90}$. Nat Commun 8(1): 589. doi: 10.1038/s41467-017-00726-x

5. Zhou X, Wang JL, Lu J, Song Y, Kwak KS, Jiao Q, Rosenfeld R, Chen Q, Boone T, Simonet WS, Lacey DL, Goldberg AL, Han HQ (2010). Reversal of cancer cachexia and muscle wasting by ActRIIB antagonism leads to prolonged survival. Cell 142(4): 531-543. doi: 10.1016/j.cell.2010.07.011

6. Penna F, Costamagna D, Pin F, Camperi A, Fanzani A, Chiarpotto EM, Cavallini G, Bonelli G, Baccino FM, Costelli P (2013). Autophagic degradation contributes to muscle wasting in cancer cachexia. Am J Pathol 182(4): 1367-1378. doi: 10.1016/j.ajpath.2012.12.023

7. Bohnert KR, Gallot YS, Sato S, Xiong G, Hindi SM, Kumar A (2016). Inhibition of ER stress and unfolding protein response pathways causes skeletal muscle wasting during cancer cachexia. FASEB J 30(9): 3053-3068. doi: 10.1096/fj.201600250RR

8. Talbert EE, Metzger GA, He WA, Guttridge DC (2014). Modeling human cancer cachexia in colon 26 tumor-bearing adult mice. J Cachexia Sarcopenia Muscle 5(4): 321-328. doi: 10.1007/s13539-014$0141-2$

9. Zhang G, Liu Z, Ding H, Miao H, Garcia JM, Li YP (2017). Toll-like receptor 4 mediates Lewis lung carcinoma-induced muscle wasting via coordinate activation of protein degradation pathways. Sci Rep 7(1): 2273. doi: 10.1038/s41598-017-02347-2

10. Aversa Z, Pin F, Lucia S, Penna F, Verzaro R, Fazi M, Colasante G, Tirone A, Rossi Fanelli F, Ramaccini C, Costelli P, Muscaritoli M (2016). Autophagy is induced in the skeletal muscle of cachectic cancer patients. Sci Rep 6: 30340. doi: 10.1038/srep30340

11. Stephens NA, Skipworth RJ, Gallagher IJ, Greig CA, Guttridge DC, Ross JA, Fearon KC (2015). Evaluating potential biomarkers of cachexia and survival in skeletal muscle of upper gastrointestinal cancer patients. J Cachexia Sarcopenia Muscle 6(1): 53-61. doi: 10.1002/jcsm.12005
Please cite this article as: Zhelong Liu, Ka Wai Thomas Sin, Hui Ding, HoangAnh Amy Doan, Song Gao, Hongyu Miao, Yahui Wei, Yiman Wang, Guohua Zhang, and Yi-Ping Li (2018). p38 $\beta$ MAPK mediates ULK1-dependent induction of autophagy in skeletal muscle of tumor-bearing mice. Cell Stress 2(11): 311-324. doi: 10.15698/cst2018.11.163

12. Op den Kamp CM, Langen RC, Snepvangers FJ, de Theije CC, Schellekens JM, Laugs F, Dingemans AM, Schols AM (2013). Nuclear transcription factor kappa B activation and protein turnover adaptations in skeletal muscle of patients with progressive stages of lung cancer cachexia. Am J Clin Nutr 98(3): 738-748. doi: 10.3945/ajcn.113.058388

13. Bechet D, Tassa A, Taillandier D, Combaret L, Attaix D (2005). Lysosomal proteolysis in skeletal muscle. Int J Biochem Cell Biol 37(10): 2098-2114. doi: 10.1016/j.biocel.2005.02.029

14. Kirkin V, McEwan DG, Novak I, Dikic I (2009). A role for ubiquitin in selective autophagy. Mol Cell 34(3): 259-269. doi: 10.1016/j.molcel.2009.04.026

15. Doyle A, Zhang G, Abdel Fattah EA, Eissa NT, Li YP (2011). Toll-like receptor 4 mediates lipopolysaccharide-induced muscle catabolism via coordinate activation of ubiquitin-proteasome and autophagylysosome pathways. FASEB J 25(1): 99-110. doi: 10.1096/fj.10-164152

16. Bianchi ME (2007). DAMPs, PAMPs and alarmins: all we need to know about danger. J Leukoc Biol 81(1): 1-5. doi: 10.1189/jlb.0306164

17. Cannon TY, Guttridge D, Dahlman J, George JR, Lai V, Shores C, Buzkova P, Couch ME (2007). The effect of altered Toll-like receptor 4 signaling on cancer cachexia. Arch Otolaryngol Head Neck Surg 133(12): 1263-1269. doi: 10.1001/archotol.133.12.1263

18. Zhao J, Brault JJ, Schild A, Cao P, Sandri M, Schiaffino S, Lecker SH, Goldberg AL (2007). FoxO3 coordinately activates protein degradation by the autophagic/lysosomal and proteasomal pathways in atrophying muscle cells. Cell Metab 6(6): 472-483. doi: 10.1016/j.cmet.2007.11.004

19. Milan G, Romanello V, Pescatore F, Armani A, Paik JH, Frasson L, Seydel A, Zhao J, Abraham R, Goldberg AL, Blaauw B, DePinho RA, Sandri $M$ (2015). Regulation of autophagy and the ubiquitinproteasome system by the FoxO transcriptional network during muscle atrophy. Nat Commun 6: 6670. doi: 10.1038/ncomms7670

20. Penna F, Bonetto A, Muscaritoli M, Costamagna D, Minero VG, Bonelli G, Rossi Fanelli F, Baccino FM, Costelli P (2010). Muscle atrophy in experimental cancer cachexia: is the IGF-1 signaling pathway involved? Int J Cancer 127(7): 1706-1717. doi: 10.1002/ijc. 25146

21. Zhang G, Jin B, Li YP (2011). C/EBPbeta mediates tumour-induced ubiquitin ligase atrogin1/MAFbx upregulation and muscle wasting. EMBO J 30(20): 4323-4335. doi: 10.1038/emboj.2011.292

22. Sandri M, Sandri C, Gilbert A, Skurk C, Calabria E, Picard A, Walsh K, Schiaffino S, Lecker SH, Goldberg AL (2004). Foxo transcription factors induce the atrophy-related ubiquitin ligase atrogin-1 and cause skeletal muscle atrophy. Cell 117(3): 399-412. doi: 10.1016/s00928674(04)00400-3

23. McClung JM, Judge AR, Powers SK, Yan Z (2010). p38 MAPK links oxidative stress to autophagy-related gene expression in cachectic 
muscle wasting. Am J Physiol Cell Physiol 298(3): C542-549. doi: 10.1152/ajpcell.00192.2009

24. Li YP, Chen Y, John J, Moylan J, Jin B, Mann DL, Reid MB (2005). TNF-alpha acts via p38 MAPK to stimulate expression of the ubiquitin ligase atrogin1/MAFbx in skeletal muscle. FASEB J 19(3): 362-370. doi: 10.1096/fj.04-2364com

25. Puppa MJ, Gao S, Narsale AA, Carson JA (2014). Skeletal muscle glycoprotein 130's role in Lewis lung carcinoma-induced cachexia. FASEB J 28(2): 998-1009. doi: 10.1096/fj.13-240580

26. Li W, Moylan JS, Chambers MA, Smith J, Reid MB (2009). Interleukin-1 stimulates catabolism in $\mathrm{C} 2 \mathrm{C} 12$ myotubes. Am J Physiol Cell Physiol 297(3): C706-714. doi: 10.1152/ajpcell.00626.2008

27. Li H, Mittal A, Paul PK, Kumar M, Srivastava DS, Tyagi SC, Kumar A (2009). Tumor necrosis factor-related weak inducer of apoptosis augments matrix metalloproteinase 9 (MMP-9) production in skeletal muscle through the activation of nuclear factor-kappaB-inducing kinase and p38 mitogen-activated protein kinase: a potential role of MMP-9 in myopathy. J Biol Chem 284(7): 4439-4450. doi: 10.1074/jbc.M805546200

28. Ding $H$, Zhang G, Sin KW, Liu Z, Lin RK, Li M, Li YP (2016). Activin A induces skeletal muscle catabolism via p38beta mitogen-activated protein kinase. J Cachexia Sarcopenia Muscle. doi: 10.1002/jcsm.12145

29. Zhang G, Li YP (2012). p38beta MAPK upregulates atrogin1/MAFbx by specific phosphorylation of C/EBPbeta. Skelet Muscle 2(1): 20. doi: 10.1186/2044-5040-2-20

30. Pogozelski AR, Geng T, Li P, Yin X, Lira VA, Zhang M, Chi JT, Yan Z (2009). p38gamma mitogen-activated protein kinase is a key regulator in skeletal muscle metabolic adaptation in mice. PLoS One 4(11): e7934. doi: 10.1371/journal.pone.0007934

31. Beardmore VA, Hinton HJ, Eftychi C, Apostolaki M, Armaka M, Darragh J, Mcllrath J, Carr JM, Armit L, Clacher C, Malone L, Kollias G, Arthur JS (2005). Generation and characterization of p38beta (MAPK11) gene-targeted mice. Mol Cell Biol 25(23): 10454-10464. doi: 10.1128/MCB.25.23.10454-10464.2005

32. Zhang G, Lin RK, Kwon YT, Li YP (2013). Signaling mechanism of tumor cell-induced up-regulation of E3 ubiquitin ligase UBR2. FASEB J 27(7): 2893-2901. doi: 10.1096/fj.12-222711

33. Mizushima N, Yoshimori T, Ohsumi Y (2011). The role of Atg proteins in autophagosome formation. Annu Rev Cell Dev Biol 27: 107-132. doi: 10.1146/annurev-cellbio-092910-154005

34. Lin MG, Hurley JH (2016). Structure and function of the ULK1 complex in autophagy. Curr Opin Cell Biol 39(61-68. doi: 10.1016/j.ceb.2016.02.010

35. Bach $M$, Larance $M$, James $D E$, Ramm $G$ (2011). The serine/threonine kinase ULK1 is a target of multiple phosphorylation events. Biochem J 440(2): 283-291. doi: 10.1042/BJ20101894

36. Egan DF, Shackelford DB, Mihaylova MM, Gelino S, Kohnz RA, Mair W, Vasquez DS, Joshi A, Gwinn DM, Taylor R, Asara JM, Fitzpatrick J, Dillin A, Viollet B, Kundu M, Hansen M, Shaw RJ (2011). Phosphorylation of ULK1 (hATG1) by AMP-activated protein kinase connects energy sensing to mitophagy. Science 331(6016): 456-461. doi: 10.1126/science.1196371

37. Puppa MJ, Murphy EA, Fayad R, Hand GA, Carson JA (2014). Cachectic skeletal muscle response to a novel bout of low-frequency stimulation. J Appl Physiol 116(8): 1078-1087. doi: 10.1152/japplphysiol.01270.2013

38. Zhou G, Myers R, Li Y, Chen Y, Shen X, Fenyk-Melody J, Wu M, Ventre J, Doebber T, Fuji N, Musi N, Hirshman MF, Goodyear L, Moller DE (2001). Role of AMP-activated protein kinase in mechanism of metformin action. J Clin Invest 108(8): 1167-1174. doi: 10.1172/JCl13505

39. Kim J, Kundu M, Viollet B, Guan KL (2011). AMPK and mTOR regulate autophagy through direct phosphorylation of Ulk1. Nat Cell Biol 13(2): 132-141. doi: 10.1038/ncb2152

40. Tanaka A, Jin Y, Lee SJ, Zhang M, Kim HP, Stolz DB, Ryter SW, Choi AM (2012). Hyperoxia-induced LC3B interacts with the Fas apoptotic pathway in epithelial cell death. Am J Respir Cell Mol Biol 46(4): 507514. doi: $10.1165 / \mathrm{rcmb} .2009-04150 \mathrm{C}$

41. Tsukahara T, Matsuda Y, Usui Y, Haniu H (2013). Highly purified, multi-wall carbon nanotubes induce light-chain $3 B$ expression in human lung cells. Biochem Biophys Res Commun 440(2): 348-353. doi: 10.1016/j.bbrc.2013.09.089

42. Mammucari C, Milan G, Romanello V, Masiero E, Rudolf R, Del Piccolo P, Burden SJ, Di Lisi R, Sandri C, Zhao J, Goldberg AL, Schiaffino $S$, Sandri M (2007). FoxO3 controls autophagy in skeletal muscle in vivo. Cell Metab 6(6): 458-471. doi: 10.1016/j.cmet.2007.11.001

43. Segatto M, Fittipaldi R, Pin F, Sartori R, Dae Ko K, Zare H, Fenizia C, Zanchettin G, Pierobon ES, Hatakeyama S, Sperti C, Merigliano S, Sandri M, Filippakopoulos P, Costelli P, Sartorelli V, Caretti G (2017). Epigenetic targeting of bromodomain protein BRD4 counteracts cancer cachexia and prolongs survival. Nat Commun 8(1): 1707. doi: 10.1038/s41467-017-01645-7

44. O'Keefe SJ, Mudgett JS, Cupo S, Parsons JN, Chartrain NA, Fitzgerald C, Chen SL, Lowitz K, Rasa C, Visco D, Luell S, Carballo-Jane $E$, Owens K, Zaller DM (2007). Chemical genetics define the roles of p38alpha and p38beta in acute and chronic inflammation. J Biol Chem 282(48): 34663-34671. doi: 10.1074/jbc.M704236200

45. Sicard P, Clark JE, Jacquet S, Mohammadi S, Arthur JS, O'Keefe SJ, Marber MS (2010). The activation of p38 alpha, and not p38 beta, mitogen-activated protein kinase is required for ischemic preconditioning. J Mol Cell Cardiol 48(6): 1324-1328. doi: 10.1016/j.yjmcc.2010.02.013

46. Perdiguero E, Ruiz-Bonilla V, Gresh L, Hui L, Ballestar E, SousaVictor P, Baeza-Raja B, Jardi M, Bosch-Comas A, Esteller M, Caelles C, Serrano AL, Wagner EF, Munoz-Canoves $P$ (2007). Genetic analysis of p38 MAP kinases in myogenesis: fundamental role of p38alpha in abrogating myoblast proliferation. EMBO J 26(5): 1245-1256. doi: 10.1038/sj.emboj.7601587

47. Palacios D, Mozzetta C, Consalvi S, Caretti G, Saccone V, Proserpio V, Marquez VE, Valente S, Mai A, Forcales SV, Sartorelli V, Puri PL (2010). TNF/p38alpha/polycomb signaling to Pax7 locus in satellite cells links inflammation to the epigenetic control of muscle regeneration. Cell Stem Cell 7(4): 455-469. doi: 10.1016/j.stem.2010.08.013

48. Gillespie MA, Le Grand F, Scime A, Kuang S, von Maltzahn J, Seale V, Cuenda A, Ranish JA, Rudnicki MA (2009). p38-\{gamma\}-dependent gene silencing restricts entry into the myogenic differentiation program. J Cell Biol 187(7): 991-1005. doi: 10.1083/jcb.200907037

49. Ho RC, Alcazar O, Fujii N, Hirshman MF, Goodyear L (2004). p38gamma MAPK regulation of glucose transporter expression and glucose uptake in L6 myotubes and mouse skeletal muscle. Am J Physiol Regul Integr Comp Physiol 286(2): R342-349. doi: 10.1152/ajpregu.00563.2003

50. Xu Y, Liu XD, Gong X, Eissa NT (2008). Signaling pathway of autophagy associated with innate immunity. Autophagy 4(1): 110112. doi: 10.4161/auto.5225

51. Zhong W, Zhu H, Sheng F, Tian Y, Zhou J, Chen Y, Li S, Lin J (2014). Activation of the MAPK11/12/13/14 (p38 MAPK) pathway regulates the transcription of autophagy genes in response to oxidative stress 
induced by a novel copper complex in HeLa cells. Autophagy 10(7): 1285-1300. doi: 10.4161/auto.28789

52. Matsuzawa T, Kim BH, Shenoy AR, Kamitani S, Miyake M, Macmicking JD (2012). IFN-gamma elicits macrophage autophagy via the p38 MAPK signaling pathway. J Immunol 189(2): 813-818. doi: 10.4049/jimmunol.1102041

53. Yu Y, Li S, Wang Z, He J, Ding Y, Zhang H, Yu W, Shi Y, Cui Z, Wang $X$, Wang $Z$, Sun L, Zhang R, Du H, Zhu Z (2017). Interferon regulatory factor-1 activates autophagy to aggravate hepatic ischemiareperfusion injury via the P38/P62 pathway in mice. Sci Rep 7: 43684. doi: $10.1038 /$ srep43684

54. Moruno-Manchon JF, Perez-Jimenez E, Knecht E (2013). Glucose induces autophagy under starvation conditions by a p38 MAPKdependent pathway. Biochem J 449(2): 497-506. doi: 10.1042/BJ20121122
55. Xu Y, Jagannath C, Liu XD, Sharafkhaneh A, Kolodziejska KE, Eissa NT (2007). Toll-like receptor 4 is a sensor for autophagy associated with innate immunity. Immunity 27(1): 135-144. doi: 10.1016/j.immuni.2007.05.022

56. Sterneck E, Tessarollo L, Johnson PF (1997). An essential role for C/EBPbeta in female reproduction. Genes Dev 11(17): 2153-2162. doi: 10.1101/gad.11.17.2153

57. Askari N, Beenstock J, Livnah O, Engelberg D (2009). p38 is Active $<\mathrm{i}>$ in vitro $</ \mathrm{i}>$ and $<\mathrm{i}>\mathrm{in}$ vivo $</ \mathrm{i}>$ When Monophosphorylated on Thr180. Biochemistry 24(48). doi: 10.1021/bi900024v

58. Avitzour M, Diskin R, Raboy B, Askari N, Engelberg D, Livnah O (2007). Intrinsically active variants of all human p38 isoforms. Febs J 274(4): 963-975. doi: 10.1111/j.1742-4658.2007.05644.x 